\title{
THE EFFECT OF RANGE OF MOTION PRACTICE ON VASCULARITY OF FEET IN PATIENTS WITH DIABETES MELLITUS IN KUDUS, CENTRAL JAVA
}

\author{
Sukarmin, A. Nor Syafik \\ School of Health Sciences Muhammadiyah, Kudus
}

\begin{abstract}
Background: Diabetes is associated with both microvascular and macrovascular impairment affecting several organs, including muscle, skin, heart, brain, and kidneys. It is increasingly important for physical therapists to be aware of diabetesrelated vascular complications. Range of motion (ROM) is the normal amount a person's joints can be moved in certain directions, or the range in which one can move a body part around a joint. ROM practice aims to recover the normal distance and direction through which a joint can move. This study aimed to examine the effect of ROM practice on vascularity of feet in patients with diabetes mellitus (DM) in Kudus, Central Java.

Subjects and Method: This was a quasi-experiment (non-randomized) before and after with control group design conducted at Puskesmas (community health center) Jepang Mejobo, Kudus, Central Java. A sample of 38 patients with DM was selected for this study, which was divided in 2 groups: 19 patients with ROM practice and 19 patients without ROM practice. The dependent variable was vascularity of feet. The independent variable was ROM practice. The data of patient with DM were obtained from the medical record. The data of vascularity of feet was measured by ankle brachial index (ABI). The other data were collected by questionnaire. The data were analyzed by Mann-Whitney test.

Results: Improvement in vascularity before and after the intervention in the experimental (ROM practice) group and was higher than in the control group, and it was statistically significant.
\end{abstract}

Conclusion: ROM practice is effective to improve vascularity of feet in patient with diabetes mellitus.

Keywords: diabetes mellitus, range of motion, vascularity, feet

\section{Correspondence:}

Sukarmin. School of Health Sciences Muhammadiyah, Kudus, Central Java.

Email: sukarmin@stikesmuhkudus.ac.id. Mobile: 08156519196 